\title{
The Effect of Using Different Interactive Modes of Activity to Improve the Acquisition of English Words for Young Learners
}

\author{
Dr. Elham Sweilam Ahmad Desouky \\ October 6 University, Faculty of Education \\ Curriculum \& Instruction (TEFL) Department \\ Email: elesweilam@gmail.com
}

\begin{abstract}
Most young learners show advanced-level incidental learning of English words when they are exposed to a certain form of the words many times, such as listening to the word and then seeing it in a picture that shows the meaning. However, the most important question here is whether young learners reach the same advanced level if the researcher reduces the time of exposure to different interactive modes level of activity. The current study attempts to determine whether evidence supports the use of interactive modes of activity in improving learners. To this end, the current research randomly allocated 144 participants. The first incidental mode was used in the present study as an incidental learning approach, whereby students were asked to learn English words based on repeated exposure to word forms. The second mode investigated the extent to which students were able to reconstruct vocabulary items based on exposure using a 2- to 6-track incidental learning technique. In track 2, the participants were asked to provide complete words that they had previously learned on a test that contained only part of those vocabulary items. The findings of the present study reported that the students' performance was better than before for the words they had prior knowledge about; the incidental learning was effective after using different interactive modes of activity. Furthermore, the present study found that repeating the form of the words several times to encourage students had a good effect initially, but that effect decreased over time.
\end{abstract}

KEY WORDS: English words; young learner; interactive modes of activity

Many learners find it difficult to gain a sufficient amount of English vocabulary, so a very common question that learners ask when starting the study of English language is how many words they need to know in order to be conversationally fluent for everyday talk in English language. Bisson, van Heuven, Conklin, and Tunney (2014) claimed that highly educated native speakers have a vocabulary of approximately 10,000 word families, producing nearly 35,000 words. But De Groot and van Hell (2005) considered this number of words to be insufficient for understanding or interacting with speakers as learners still needs more words that they can acquire through an instructional setting. For this 
reason, the importance of using the incidental approach to learning words emerged.

The incidental approach to learning is the process whereby learners learn something without the intention of doing so. It is also learning one thing while intending to learn another, as the learners are not asked directly to learn something (Williams, 2010). Horst (2005) explained that learning can occur just by showing the tools of learning through a variety of duties; after that, the instructor can give a surprise test to measure if the learners can recognize the word and understand it, so they will be able to choose the right word and answer the test. De Groot and van Hell (2005) tried to show the difference between incidental learning and explicit learning: The aim of the learner in incidental learning is to understand the content or enjoy learning whereas in explicit learning, the learner's target is to remember information and combine the foreign language word and its meaning in their native language.

Williams (2010) said that incidental word acquisition can be regarded as non-explicit in so far as it does not involve an explicit learning intention (i.e., the overall goal of the learner is text comprehension and not word acquisition). With regard to the role of consciousness, two complementary viewpoints can be distinguished. An implicit viewpoint would hold that incidental word acquisition takes place without awareness, involving only implicit learning processes. But this viewpoint fails to take into account the fact that learners are active and information analysts. An explicit viewpoint would thus argue that incidental word acquisition also involves explicit (i.e., conscious) learning processes and would consequently characterize it as primarily explicit learning.

Although incidental learning has been defined as the process in which learners learn something without the intention of doing so, scholars have often used incidental learning in teaching language in the classrooms where their objectives to learn are clear, meaning it is not obvious whether the learning was intentional or not. Most importantly, the learner's concentration is on comprehension rather than anything else, meaning learning happens as a margin to something else (Schmitt, 2010). Moreover, when researchers use incidental learning techniques, they care about the amount of learning rather than learners' awareness. The present research tried to use incidental learning to show learning that occurred just through exposure to the language. In addition, the learners who took 
part in this study were not informed about the new words being learned or the words included in the task.

Vidal (2011) claimed that many elements affect the incidental acquisition of words, such as how many times the learner should be exposed to the new word as well as the kind of words, whether they are similar to any words in the learner's native language, and the learner's ability to predict the form of words in the target language. Despite the important studies that have concentrated on incidental learning from reading (e.g., Schmitt, 2010; Vidal, 2011), no one can determine the exact number needed to show words in other situations, like different interactive modes of activity where the researcher deals with learners studying English for the first time or trying to combine auditory, written, and visual cues in the same content.

In Bisson, van Heuven, Conklin, and Tunney's (2013) research, the participants were young learners studying English for the first time. The researchers showed the new words eight times using a multimodal incidental learning situation. But can young learners learn new English words even when shown these words fewer times? If incidental learning of new words occurs with less exposure but the researcher increases the number of times the new words are shown, will acquisition of these words increase?

Ebbinghaus (1964) conducted a series of important studies showing the effects of repeating words on memory and learning. He divided his study into stages. In stage one, he broke the words into syllables to be able to read them; exposure to the syllables increased from 8 to 64 times, and he succeeded in showing achieving learning through reading. After the first stage, Ebbinghaus assessed his study and found that less time was taken to relearn syllables than to learn them initially. Furthermore, the more he increased the exposure during the learning stage, the less time he used to learn syllables the next day, meaning that the repeated exposure had a good effect on learning.

Many researchers have considered Ebbinghaus's (1964) ideas when trying to measure the effects of showing new words several times during incidental learning. The next part of this study reviews these studies. 


\section{Review of Previous Research}

The part includes four sections that discuss studies on incidental word acquisition through reading, listening, and reading-while-listening as well as studies using different interactive modes of activity.

\section{Incidental Word Acquisition through Reading}

Schmitt (2010) examined whether participants acquire new words through reading. He decided to use these words in a meaningful context through a novel. Schmitt asked his students to read a specific novel containing 34 new words they saw for the first time. These words were not English words, but actually an African dialect among English content. He divided these words into five groups according to the number of their occurrences in the text; some of these words were shown once whereas some others were shown up to 28 times. The study's results indicated that the participants acquired 9 of the 34 new words. Furthermore, the results indicated the positive effect of repeating the words as the learners were interacting positively: The more the researcher repeated the word, the more the learners gained new words. The learners also learned words by reading the novel.

Instead of using a novel, Vidal (2011) decided to use three university lectures in English and asked her students, who were native Spanish speakers, to read the lectures to determine how many new words they would learn. Vidal measured participants' reading level before and after reading the three English lectures and found that the learners acquired up to 19 of the 36 new words while the number of times of exposure ranged from one to six. Vidal did not create her own reading material; she used authentic reading material so the number of exposures to the new words was not equal.

Rott (1999) designed her own reading material to examine the incidental acquisition of words through reading. She wrote a group of short paragraphs, with each paragraph containing new words. The learners read the paragraphs once a week. Rott divided her experiment into three stages. In stage one, she showed the new words several (two to six) times and then asked the learners to complete a productive vocabulary task and finally determine a definition by completing a receptive vocabulary task to evaluate the acquisition of the new words. Rott found that participants exposed to the new words six times achieved a more advanced level than those exposed just two or four times. In 
addition, learners scored higher on words to which they were exposed compared to words to which they were not exposed. The researcher found that these studies demonstrated that the learner should be exposed to new words several times in a meaningful content to achieve word acquisition.

Other researchers tried to work on incidental word learning by using electroencephalography (EEG) to record event-related potentials. For example, Batterink and Neville (2011) focused on the N400 factor to discover the importance of this component when learning new words. They used new words from short stories and showed these words several times (up to 10 times). The results showed that the learners achieved a low level on the $\mathrm{N} 400$ for the new words with a consistent meaning compared to novel words for which no consistent meaning could be derived; the controlling factor here for the effect was the result of repeating the form of the word only. In addition, the researchers mentioned that the difference between the two types of the new words happened faster than they expected, as it appeared when they showed the words the second time.

In Mestres-Missé, Rodriguez-Fornells, and Münte's (2007) study, the learners read triplets of sentences in meaningful content. The results showed that, after three exposures to the new words, the learners could not distinguish between the N400 element for the new words and the known words. Furthermore, the learning occurred early, after only one exposure to the new words. The researchers concluded that the N400 capacity was reduced when using the new words without exaggeration, and the effects of early learning was clear either when showing the new words or directly after the exposure. Thus, the question is whether these effects will last for a long time or not. The researchers also noted that, in previous studies, learners were aware of the aim of the studies and were asked to derive the meaning of the new words from meaningful context, which is different from incidental learning. Researchers can derive from these studies that the learning can occur when putting the new words in a meaningful context and showing them fewer times.

\section{Incidental Word Acquisition through Listening}

Some studies tried to investigate the incidental learning of new words through listening. Vidal (2011) compared two groups of learners after giving them three university lectures. In group one, she repeated exposures of new words while learners listened to the lectures; in group two, the learners were read the lectures. Vidal found that she could not depend on the frequency of exposures for the learners who listened to the 
lectures because all the tests were conducted through reading only whereas the participants in the listening case had exposure to the new words through listening only. Using different ways of learning and testing may have had a negative effect on giving true results about students' acquisition of the new words. Despite this result, Vidal found that the learners acquired about 12 words after listening to the three lectures.

Brown, Waring, and Donkaewbua (2008) also tried to determine the effect of acquiring new words through listening by asking the groups of participants to listen to a foreign language story containing 28 new words they wanted the learners to acquire. They showed participants these words several times, ranging from 2 to 20 times. The results demonstrated that the learners were able to gain about eight new words, and the number of exposures had no effect on word recognition or delivery of them in the test. In contrast to Vidal's (2011) study, Brown et al. (2008) assessed learners through a listening test and the participants shared in reading and reading-while-listening sessions followed by a test, so the participants were expecting to have a word test. It is clear that this study did not use a control group or control items, although it was important to use them to prove that understanding of the new words was due to incidental learning.

\section{Incidental Word Acquisition through Reading-While-Listening}

The incidental word acquisition through reading-while-listening seemed to be interesting for many researchers, as the learners listen to the pronunciation of the words while concentrating on the written words, which helped learners divide any word into syllables to make it easier for them to acquire. Brown et al. (2008) examined incidental word acquisition through reading-while-listening. They asked participants to read some stories while listening to them. They found that learners were able to remember more words that appeared in the events of the stories several times than other words. Brown et al. discovered that the repetition of exposure to the new words in the stories (ranging from 2 to 13 times) led to better remembering of the new words, but greater repetition did not lead to any further improvement.

Webb, Newton, and Chang (2013) examined the incidental learning of words through reading-while-listening to stories, but they used multiple word units to increase the chance of learning. Webb et al. made some modifications to the stories' content so they could expose participants to the 18 word units several (i.e., 1 to 15 ) times. They found 
that the learners were able to recognize the form of the word units after 5 exposures and remember them after 10 exposures whereas incidental learning of the meaning required 15 exposures when they introduced the meaning of the word units to the learners and 10 exposures at the productive level. The researchers also found that the experimental group gained greater knowledge after being exposed to the word units several times (up to 15 times).

These studies using reading, listening, and reading-while-listening in incidental learning situations involved learners who were native speakers or intermediate or advanced foreign language learners. The researchers asked the participants to understand the meaning of the words through the novel content and observed if it would be difficult for the beginners in a foreign language to study incidental acquisition in such situations because the learners did not have enough knowledge to dive into the depth of the novel and understand the meaning of the words. Meanwhile, Schmitt (2010) found that learners must know about $95 \%$ of the words in the content to be able to understand the meaning. In fact, the learners need an easy way to facilitate meaning acquisition of new foreign language words. Thus, Webb and Rodgers (2009) suggested using images such as television programs by combining foreign language content and image information. The next part of this study will discuss this issue.

\section{Using Different Interactive Modes of Activity}

Webb and Rodgers (2009) suggested using images, which the current researcher found interesting. First, the researcher thought that a lot of studies would have searched for the importance of using interactive modes of activity, but only a few recent studies have used interactive modes of activity to test incidental learning acquisition of foreign language words. Bisson et al. (2014) tried to investigate the effect of using auditory and written foreign language word forms combined with pictorial information. The effect of the incidental learning appeared after eight exposures to the words. Although the learners had no previous information about the words, they were able to recognize the meaning of the words in the task after the incidental learning situation. Bisson et al. found that participants' ability to recognize the meaning of the words was due to the use of pictorial information.

Gullberg, Roberts, and Dimroth (2012) asked participants to watch a Chinese weather bulletin once or twice without any previous information. They gave the participants a task after watching the bulletin and asked them to mention if the Chinese words had appeared in it or not. 
The participants were able to recognize the words to which they were exposed several times (i.e., 8 to 16 times) more than the words to which they were exposed fewer times (i.e., 2 to 4 times). Bisson et al. (2014) commented on this study, saying:

"Unfortunately, it is not clear whether the accuracy scores for each number of occurrences were significantly above chance. Furthermore, no control items were included in the study. Therefore it is difficult to determine whether the higher accuracy scores for the more frequent items were due to the number of occurrences of the items or whether the items themselves were easier to recognize". (p. 870)

After reviewing the previous studies, the current researcher determined that there was not enough information about the number of exposures that any study needs to use to help participants learn the form and meaning of the new words. In addition, any researcher should consider the choice of the right method to use to assess the learners' acquisition of words. Some previous studies did not use control groups or control items, making it difficult to know whether the high scores of the items were due to the number of exposures or the items themselves were easy for the participants to recognize faster. Furthermore, some studies tried to clarify the changes that participants experienced before and after the study by using a pre-/posttest, which might cause problems by making learners aware of the word-learning and drawing their attention to certain words. The researcher also found that a few recent studies have used interactive modes of activity to test the incidental learning acquisition of foreign language words among young learners (beginners). Thus, the present research aimed to examine if repeated exposure will result in good efficacy among young participants (beginners) when they acquire new words.

The present study followed two tracks: incidental learning using interactive modes of activity (track 1) and explicit learning (track 2). In track 1, participants were asked to learn new English words; half of these words had been presented in the incidental learning stage whereas the other half of the words were completely new. The number of exposure to the words ranged between 2 and 6, using 10 words in every exposure and one set of items. In track 2, the young learners were exposed to the new English words and another set of items; this track was used as a control comparison in explicit learning. 


\section{Participants}

\section{Method}

One hundred forty-four learners participated in this study. Their age ranged from 6 to 6.5 years old. All of them were from the countryside Qaliobia governorate in Othman Ibn Affan governmental school. All participants were native speakers of Arabic, and the researcher verified that the participants had not studied English and did not know any English words. The researcher also used some English words and asked participant if they knew the words or their meaning. They answered "no." To verify this, the researcher administered a test, but the participants could not match the right word with the right picture. The researcher excluded 10 participants who had engaged in English lessons in K.G. before they joined the school.

\section{Study Design}

The current study utilized a repeated-measures design for this experiment with type of word (old and new) as well as number of exposures during the first stage (incidental learning). The researcher used 80 English words (taken from the student book Time for English, 20162017) and considered the presentation of words in three ways - auditory, written, and images - to clarify the meaning. All the words used in this study were easy for the participants to recognize as they did not need ideas or concepts (see Appendix 1). The words were divided into two stages; the first stage included words used in incidental learning whereas, in the second stage (explicit learning), the words presented in the first stage (incidental learning) were considered old words while the words seen for the first time (explicit learning) were considered new words.

The first stage (incidental learning) included 40 words; the researcher broke this group into small blocks containing 10 words each. The words were presented several times, up to six times. To ensure that the words in the blocks were not at differing levels with regard to ease of use and difficulty, suggesting that the participants might learn some words faster than others, the researcher arranged the small blocks to be equal in terms of ease of use and difficulty.

\section{Procedures}

The researcher divided the experiment into two sections. Section one (incidental learning) presented half of the English words and used a letter-search task. No one told the participants that the foreign language was English, and they were not asked to learn the words. This research used interactive modes of activity to present the English words first. The 
participants were then asked to listen to the auditory English words once while images clarifying the meaning of the English words and the written form of the words appeared on the screen. This method helped the participants get an understanding based on the meaning of the images and the English words. The researcher left the image and the written form of the English word on the screen for some time until participants responded. The participants were asked to complete the letter-search task, and they were interactive participants as they completed two hundred trials (in which word exposure ranged from 2 to 6 times).

After the researcher finished section one, she immediately began section two (explicit learning), in which participants were asked to learn English words and complete a translation recognition task. In this section, both groups of words were used; the words used in incidental learning were considered old words while the remaining words used in explicit learning were considered new words. No one told the participants that they had previously seen half of the words in the incidental learning stage. The researcher presented the auditory form of English words simultaneously with their Arabic translation. Participants' task was to say whether the Arabic word was the correct translation for the auditory English word.

The researcher told the participants immediately whether their answers were right or wrong, and she asked them to learn the correct translation from this feedback. As previously mentioned, the researcher broke the groups of words into blocks, with each containing 10 words. The participants were told that their mission was to find the correct answers for most of the words in one block (85\% exactly) or the examiner (i.e., the researcher) would continue with them in the following blocks until they reach the targeted percent (to a maximum of three blocks). The learners also received their feedback directly after completing each block. The researcher presented each auditory English word once with the correct Arabic translation and once with wrong translation from participants' blocks (until reaching 150 attempts in every subset). The researcher found that incorrect answers stemmed from participants choosing the wrong Arabic translation for the auditory English word, and they were different in each block of attempts. 


\section{Dr. Elham Sweilam Ahmad Desouky}

\section{Results}

In the incidental learning stage, the researcher noticed that the participants were accurate in the letter-search task $(\mathrm{M}=92.7 \%)$ and responded positively to the written form (average time $=895$ milliseconds, $\mathrm{SE}=36$ milliseconds). Only one participant had a different response time (62\% in accuracy), and the researcher excluded him from further analyses. The situation in explicit learning was different as the researcher concentrated on analyzing the results of the participants and the items of block one and two while excluding block three because some participants (28) achieved standard accuracy in block two, so they did not have to use block three.

At this stage, the researcher used the number of exposures to the words in the incidental learning stage to calculate the percentage of the right answers in the translation recognition task for the old and new words (Table 1). These analyses were submitted to repeated-measures analyses of variance (ANOVAs) with word type (old versus new) and number of exposures during the incidental learning stage (two, four, and six) as insider factors for each block. The results showed an important effect on word types in block one and block two as the participants were more successful in dealing with the old words to which they were exposed in the first stage (incidental learning) whereas when dealing with new words in the explicit learning stage, their performance was less satisfactory (in subset one $F_{1}(3.3)=82.7, p<.001, \eta p^{2}=.39, F_{2}(3.52)=$ 102.86, $p<.001, \eta p^{2}=.40$, and subset two, $F_{l}(3.3)=46.18, p<.001$, $\left.\eta p^{2}=.26, F_{2}(3.52)=57.88, p<.001, \eta p^{2}=.28\right)$

The scores in block one were also significantly higher for the old words for each number of exposures, ranging from two to six exposures in the first stage (incidental learning), $F_{l}(3.3)=18.1, p<.01, \eta p^{2}=.12$, $F_{2}(3.52)=16.2, p<.01, \eta p^{2}=.09, F_{1}(3.3)=31.94, p<.001, \eta p^{2}=.20$, $F_{2}(3.52)=24.56, p<.01, \eta p^{2}=.15, F_{1}(3.3)=21.98, p<.01, \eta p^{2}=.15$, $F_{2}(3.52)=19.24, p<.01, \eta \mathrm{p}^{2}=.12, F_{1}(3.3)=55.62, p<.001, \eta \mathrm{p}^{2}=.30$, $F_{2}(3.52)=47.84, p<.001, \eta p^{2}=.30$. The good effect of exposure to the words in block one in the first stage (incidental learning) was very clear and significant in block two in the explicit learning stage after further explicit learning for the words exposed to learners twice during incidental learning $\left(F_{1}(3.3)=10.26, p<.05, \eta p^{2}=.07, F_{2}(3.52)=14.84, p<.01, \eta p^{2}\right.$ $=.10)$. For the words exposed to participants four times during the incidental learning stage, $F_{1}(3.3)=4.26, p=.15, \eta \mathrm{p}^{2}=.03, F_{2}(3.52)=$ $4.48, p=.14, \eta p^{2}=.05$. Finally, for the words exposed to participants six times in the incidental learning stage, $F_{l}(3.3)=19.4, p<.01, \eta p^{2}=.13$, $F_{2}(3.52)=16.36, p<.01, \eta p^{2}=.10$. 
Table 1.

Mean (SE) Percentage of correct answers in blocks 1 and 2 of the translation recognition task (stage 2) for both old and new words according to the number of exposures during the incidental learning phase (Stage 1).

\begin{tabular}{|c|c|c|c|c|}
\hline $\begin{array}{c}\text { Number } \\
\text { of } \\
\text { exposures }\end{array}$ & \multicolumn{2}{|c|}{ Block (1) } & \multicolumn{2}{c|}{ Block (2) } \\
\hline & Old words & $\begin{array}{c}\text { New words } \\
\text { (control) }\end{array}$ & Old words & $\begin{array}{c}\text { New } \\
\text { words } \\
\text { control) }\end{array}$ \\
\hline 2 & $62.2(2.7)$ & $56.3(2.5)$ & $77.9(2.7)$ & $73.3(2.7)$ \\
\hline 4 & $65.9(2.6)$ & $58.7(2.3)$ & $75.1(2.7)$ & $72.6(2.6)$ \\
\hline 6 & $67.4(2.6)$ & 60.9 & $78.0(2.4)$ & $73.2(2.4)$ \\
\hline
\end{tabular}

Table 1 showed the percentage of correct answers for old and new words in the translation recognition task that occurred in stage two (explicit learning) according to the number of exposures that took place during the incidental learning stage. In addition, the new words were not used in the incidental learning, but the researcher divided them into blocks for control comparison to use in the analysis.

The researcher used computing linear contrasts using a repeatedmeasure ANOVA in two parts: the participant analysis and a one-way ANOVA in the item analysis to measure the scores of the old and new words in incidental learning to determine if a difference existed between them after repeated exposures. The findings indicated no important differences in linear contrasts in block one, F1 (3.3) $=4.62, p=.13, \eta p^{2}=$ $.03, F_{2}(3.52)=3.28, p=.20, \eta p^{2}=.02$, or block two, $F \mathrm{~s}<1$. The researcher then used a paired sample $t$-test and an independent sample $t$ test in the participant and item analyses, respectively (one-tailed), to identify any differences in the incidental learning effect when dealing with the minimum (two) and maximum (six) number of exposures while also examining the effect of increasing the number of exposures and whether it increased the incidental learning effect or not. The findings showed a big difference between block one and block two in the 
incidental learning effect, which increased significantly in block one when dealing with the minimum (two) and maximum (six) number of exposures in two parts: the participant analysis, $t_{l}(130)=3.42, p<.05, d$ $=0.21$, and the item analysis, $t_{2}(76)=3.1, p=.06, d=0.49$. However, block two showed no significant differences in the incidental learning effect, $t \mathrm{~s}<1$.

The researcher believed that the knowledge participants gained in the first stage (incidental learning) might differ according to the number of exposures. The researcher determined that the different scores between old and new words in block one at the second stage (explicit learning) were due to the number of exposures during the first stage (incidental learning). In addition, the accuracy scores increased according to the number of exposures in the incidental learning stage. For example, the accuracy scores of the old words exposed to participants two times during the first stage (incidental learning) were higher (6\%) than the new words, meaning that accuracy increased by a rate of $3 \%$ per exposure to the words. Meanwhile, the accuracy scores of the old words with six exposures during the first stage (incidental learning) were higher than the new words, reaching 10\%; thus, the accuracy scores increased in every exposure by a rate of $1.25 \%$. The researcher used ANOVAs to examine the normal effects of the incidental learning and found a small significant negative linear trend, which means that greater exposure increased the less knowledge gained, $F_{1}(3.3)=7.96, p=.05, \eta p^{2}=.06, F_{2}(3.52)=$ 9.24, $p<.05, \eta \mathrm{p}^{2}=.05$.

\section{Discussion}

The main target of the present study was to examine whether the repeated exposure to the English words in the incidental learning stage while using interactive modes of activity had a good effect on learning. The findings revealed that participants' performance when dealing with the translation recognition task showed a good effect of the incidental learning stage, even without having previous knowledge of English words. In addition, the efficacy of the incidental learning was continuous, appearing in block one and block two in the explicit learning stage. The findings also revealed that the participants' performance improved during the second stage (explicit learning) after they were exposed the minimum number of times (two) in the first stage (incidental learning). Thus, if participants know the meaning or the form of the English words, it will be easy to acquire the words after two exposures to the interactive modes of activity in the incidental learning stage. Furthermore, when the researcher compared the scores of the minimum (two) and maximum (six) number 
of exposures, she found that participants' performance improved on the translation recognition task after more exposure during the first stage (incidental learning). But this was the only case, as the researcher did not subsequently find a comprehensive effect for the repeated exposures because the number of times showing a word was not stable in the incidental learning stage. In addition, it was clear that, when making additional showings of a word combined with the increasing number of exposures, the effect will be less during the incidental learning stage.

The current study presented the English words independent of any context combined with images, so it was easy for the participants to concentrate on the form and understand the meaning of the words early in the minimum (two) exposure. In this case, the participants did not have to dive into the depths of the text to understand the meaning of the words, like what is required during the reading, listening, and reading-whilelistening situations. Using interactive modes of activity helped the researcher present the word clearly and made it easy for the participants to make a connection between the form of the written word and the meaning of the word when presented together at the same time. As previously mentioned, this study found a learning effect in the minimum (two) exposure during incidental learning; however, this may be not enough when the participants are exposed to a complex context or ambiguous words, which need more exposures.

In addition, in the incidental learning stage, the participants had to complete a letter-search task, so they concentrated only on the written form and neglected the auditory words and images. For this reason, the participants were not interested in having more information after a few exposures or seeing more images. Thus, the unequal effect of extra exposures to English words in this research is due to the incidental learning stage itself. Furthermore, when the researcher repeated the English words more often during the incidental learning stage, participants' average response time was faster. Participants' average in each number of exposures during the incidental learning was, for the minimum exposures (two), 773 milliseconds ( $S E=23$ milliseconds); their response to words repeated four times was 737 milliseconds $(S E=22$ milliseconds), and their response to words presented six times was 750 millisecond ( $S E=21$ milliseconds), on average.

Future studies should separate the effects of repeated exposure from the effects of the period of exposure when participants spend less 


\section{Dr. Elham Sweilam Ahmad Desouky}

time on the stimuli with each exposure, even when increasing the number of exposures. Furthermore, researchers should use eye tracking to examine the effect of images and the written form of the words more specifically, which could enable them to discover the effects of increased fixed knowledge after the repetition of the stimuli. It would also be beneficial to explore the effect of the number of exposures on increased knowledge in incidental learning. In fact, the effect of the repeated number of exposures has been identified in other studies (e.g., Bisson et al., 2014; Vidal, 2011), but it is difficult to compare these studies because they used a varied number of exposures.

\section{Conclusion}

The findings of the present research highlight the importance of using interactive modes of activity in an incidental learning situation, which was sufficient for the beginners to learn new English words very fast after being exposed to these words, even with a minimum number of exposures (i.e., two). Despite this result, the effect of the exposure changed over time. Consequently, the learners will need just a limited amount of exposure before starting to learn, and this will be very helpful for the English teachers as they can use the activities they used before in incidental learning and introduce the new words at the beginning of learning. The present research revealed that, during the explicit learning stage, teachers can use a limited amount of exposure with learners. Furthermore, given the results of the current study, English teachers should use any activity to help learners understand the meaning of English words as well as acquire the form of the words, as the present research used a letter-search task as an activity in the incidental learning stage.

The researcher found it difficult to say whether the participants were able to recognize the English words during the incidental learning stage or whether this recognition was just a start to gain knowledge. Thus, it was not easy to determine the type of knowledge that participants acquired in the first stage (incidental learning), especially after the researcher gave them feedback about their answers (i.e., whether it was right or wrong) to help them acquire knowledge in the second stage (explicit learning). It is important to note that, in the first stage (incidental learning), participants were able to acquire some knowledge that gave them the power to continue and improve their performance in the second stage (explicit learning). 
The researcher also concluded that it was not clear whether the participants acquired the knowledge by using the images containing information or calling upon their native language (Arabic) when they saw the images and linked them to their native language (Arabic) and the form of the English words. Moreover, in the translation recognition task, it was not possible to link participants' ability to recognize the form and the meaning of the words as the nature of the task was not designed to do this. Future research should examine the effect of a different number of exposures over time (e.g., one to two weeks), which is different from the current research as it used an incidental learning stage and explicit learning stage in the same lecture. 


\section{Dr. Elham Sweilam Ahmad Desouky}

\section{References}

Batterink, L., \& Neville, H. (2011). Implicit and explicit mechanisms of word learning in a narrative context: An event-related potential study. Journal of Cognitive Neuroscience, 23, 3181-3196.

Bisson, M.-J., van Heuven, W. J. B., Conklin, K., \& Tunney, R. J. (2013). Incidental acquisition of foreign language vocabulary through brief multi-modal exposure. PLoS ONE, 8(4), e60912.

Bisson, M.-J., van Heuven, W. J. B., Conklin, K., \& Tunney, R. J. (2014). The role of repeated exposure to multimodal input in incidental acquisition of foreign language vocabulary. Language Learning, 64, 855-877.

Brown, R., Waring, R., \& Donkaewbua, S. (2008). Incidental vocabulary acquisition from reading, reading-while-listening and listening to stories. Reading in a Foreign Language, 20, 136-163.

De Groot, A. M. B., \& van Hell, J. G. (2005). The learning of foreign language vocabulary. In J. F. Kroll \& A. M. B. de Groot (Eds.), Handbook of bilingualism: Psycholinguistic approaches (pp. 9-29). New York: Oxford University Press.

Ebbinghaus, H. (1964). Memory: A contribution to experimental psychology. (H. A. Ruger \& C. E. Bussenius, Trans.). New York: Dover Publications. (Original work published 1885)

Gullberg, M., Roberts, L., \& Dimroth, C. (2012). What word-level knowledge can adult learners acquire after minimal exposure to a new language? The International Review of Applied Linguistics in Language Teaching, $50,239-276$.

Horst, M. (2005). Learning L2 vocabulary through extensive reading: A measurement study. Canadian Modern Language Review, 61, 355-382.

Mestres-Missé, A., Rodriguez-Fornells, A., \& Münte, T. F. (2007). Watching the brain during meaning acquisition. Cerebral Cortex, 17, 1858-1866.

Rott, S. (1999). The effect of exposure frequency on intermediate language learners' incidental vocabulary acquisition and retention through reading. Studies in Second Language Acquisition, 21, 589-619.

Schmitt, N. (2010). Researching vocabulary: A vocabulary research manual. Basingsoke, UK: Palgrave Macmillan.

Vidal, K. (2011). A comparison of the effects of reading and listening on incidental vocabulary acquisition. Language Learning, 61, 219-258.

Webb, S., Newton, J., \& Chang, A. (2013). Incidental learning of collocation. Language Learning, 63, 91-120.

Webb, S., \& Rodgers, M. P. H. (2009). Vocabulary demands of television programs. Language Learning, 59, 335-366.

Williams, J. N. (2010). Initial incidental acquisition of word order regularities: Is it just sequence learning? Language Learning, 60(S2), 221-244. 


\section{Appendix 1}

\section{List of Words Used in the Study}

This list identifies the Arabic and English words used, including the set number and number of exposures during the incidental learning stage (see Time for English, Ministry of Education, Arab Republic of Egypt, 2016-2017).

\begin{tabular}{|c|c|c|c|c|}
\hline Arabic & English & Set 1 & Set 2 & Exposures No. \\
\hline أسرة & Family & New & old & 2 \\
\hline أب & Father & New & old & 2 \\
\hline أم & Mother & New & old & 2 \\
\hline أخ أخ & Brother & New & old & 2 \\
\hline أخت & Sister & New & old & 2 \\
\hline أصدقاء & Friends & New & old & 2 \\
\hline ولد & Boy & New & old & 2 \\
\hline طائر & Bird & New & old & 2 \\
\hline نمله & Ant & New & old & 2 \\
\hline تفاحة & Apple & New & old & 2 \\
\hline زراع & Arm & New & old & 4 \\
\hline واحد & One & New & old & 4 \\
\hline إثثان & Two & New & old & 4 \\
\hline ثلاثة & Three & New & old & 4 \\
\hline أربعة - م ك & Four & New & old & 4 \\
\hline خمسة & Five & New & old & 4 \\
\hline يرسم & Draw & New & old & 4 \\
\hline يقرأ يقأ & Read & New & old & 4 \\
\hline يكتب ل بكت & Write & New & old & 4 \\
\hline 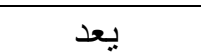 & Count & New & old & 4 \\
\hline كيكة & Cake & New & old & 6 \\
\hline سيارة & Car & New & old & 6 \\
\hline قط & Cat & New & old & 6 \\
\hline كلب & Dog & New & old & 6 \\
\hline حمار & Donkey & New & old & 6 \\
\hline عروسه لعبه & Doll & New & old & 6 \\
\hline إنهض & Stand up & New & old & 6 \\
\hline 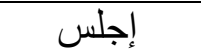 & Sit down & New & old & 6 \\
\hline إرفع يديك & Hands up & New & old & 6 \\
\hline نزل يديك & Hands down & New & old & 6 \\
\hline ثمانية & Eight & New & old & 6 \\
\hline 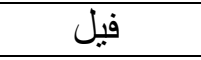 & Elephant & New & old & 6 \\
\hline بيضة & Egg & New & old & 6 \\
\hline فلاح & Farmer & New & old & 6 \\
\hline سمك & Fish & New & old & 6 \\
\hline مروحة & Fan & New & old & 6 \\
\hline لمائرة & Circle & New & old & 6 \\
\hline
\end{tabular}


Dr. Elham Sweilam Ahmad Desouky

\begin{tabular}{|c|c|c|c|c|}
\hline Arabic & English & Set 1 & Set 2 & Exposures No. \\
\hline قلب & Heart & New & old & 6 \\
\hline نجمة & Star & New & old & 6 \\
\hline مربع & Square & New & old & 6 \\
\hline يمشي & Walk & New & old & 2 \\
\hline يغوص | ليغ & Dive & New & old & 2 \\
\hline قفز & Jump & New & old & 2 \\
\hline سباحة & Swim & New & old & 2 \\
\hline بنت & Girl & New & old & 2 \\
\hline ماعز & Goat & New & old & 2 \\
\hline حديقة حدية & Garden & New & old & 2 \\
\hline حصان & Horse & New & old & 2 \\
\hline منزل من من من & House & New & old & 2 \\
\hline لدجاجة & Hen & New & old & 2 \\
\hline 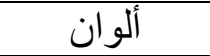 & Colors & New & old & 4 \\
\hline 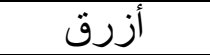 & Blue & New & old & 4 \\
\hline أحمر & Red & New & old & 4 \\
\hline أصفر & Yellow & New & old & 4 \\
\hline أخضر & Green & New & old & 4 \\
\hline 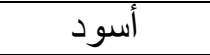 & Black & New & old & 4 \\
\hline برسم دائرة & Draw a circle & New & old & 4 \\
\hline يلون الصورة & Color the picture & New & old & 4 \\
\hline يعد النجوم & Count the stars & New & old & 4 \\
\hline يشير إلي & Point to & New & old & 4 \\
\hline القلب الاحمر & Red heart & New & old & 4 \\
\hline في & In & New & old & 4 \\
\hline حبر & Ink & New & old & 4 \\
\hline 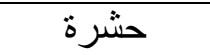 & Insect & New & old & 4 \\
\hline بنطلون جينز & Jeans & New & old & 4 \\
\hline برطمان & Jar & New & old & 4 \\
\hline جاكت & Jacket & New & old & 4 \\
\hline
\end{tabular}


The Effect of Using Different Interactive Modes of Activity to Improve the Acquisition of English Words for Young Learners 